\title{
Three arms: a case study of supernumerary phantom limb after right hemisphere stroke
}

\author{
Peter W Halligan, John C Marshall, Derick T Wade
}

\begin{abstract}
A case of supernumerary phantom limb is described after a haematoma within the right basal ganglia. The phantom, which persisted for many months, occurred in the context of severe left hemiplegia, sensory loss, hemianopia, and neglect. The subjective reality of this "third arm" caused the patient considerable distress, which was not ameliorated by his attempts to rationalise its existence. Although deeply confused by the phantom, the patient was otherwise fully oriented, with a high verbal IQ, and normal cognition. Two distinct formal interpretations of the phenomenon are discussed.
\end{abstract}

(F Neurol Neurosurg Psychiatry 1993;56:159-166)

For over a century it has been known that many patients with brain damage are unaware of the very deficits that give rise to their impaired performance in everyday life. This lack of awareness (or anosognosia) in patients who otherwise appear to have normal cognition poses serious problems for rehabilitation as they often fail to appreciate the relevance of remedial interventions and overestimate their functional abilities. ${ }^{12}$ Cutting's ${ }^{3}$ major study of anosognosia after acute stroke found that $87 \%$ of left hemiplegics showed "anosognosic phenomena"; most patients (58\%) denied left side weakness, while the remainder exhibited symptoms which ranged from a feeling of "nonbelonging" for the left limb to a lack of appropriate concern for the existing deficit (anosodiaphoria). The only "anosognosic feature", Cutting's term for "other abnormal attitudes to a weak limb", not found in his large study was belief in a phantom limb. When the real limb is present, as in the case of stroke, this phenomenon is referred to as supernumerary phantom limb ${ }^{4}$ or phantom third limb. ${ }^{56}$

Although phantom limbs occur in the vast majority of patients with limb amputations and are commonly found after avulsion or anaesthetic block of the brachial plexus, ${ }^{6}$ the persisting belief in the existence of an additional limb after unilateral stroke is very unusual. ${ }^{7}$ Indeed, its presence after stroke is not expected given clinical reports ${ }^{58}$ that cerebral lesions that compromise somatic sensation in patients with prior amputations can result in the disappearance of the phantom limb.

One of the few detailed accounts of supernumerary phantom limb after stroke is repor- ted by Ehrenwald. ${ }^{10}$ A 59 year old right hemisphere stroke patient is described who, according to his doctor, complained of having a "nest of hands in his bed". This patient, with left homonomous hemianopia and complete paralysis of the left arm and leg, requested that the "hands" should be amputated and put in a bag. Six days after the stroke, when the patient was fully oriented and aware of his hemiplegia, he maintained that his old left hand had begun to shrink and that a new hand had emerged, becoming fleshier and more voluminous. Subsequent questioning confirmed that the patient believed in the existence of several hands (without arms), two on the left and one on the right, the former of which were thought to be located in the region of his left knee. Ehrenwald notes that the patient attempted to rationalise what he was saying, "wondering about the likelihood of what was happening". The patient's condition persisted for several months after the stroke. Other patients, with right hemiplegia after left hemisphere damage, have been reported by Pineas ${ }^{11}$ and Van Bogaert. ${ }^{12}$ In the latter case, an infarct of the optic thalamus and internal capsule was confirmed at necropsy. In his book on the parietal lobes, Critchley ${ }^{4}$ briefly describes several case studies. These patients did not show anosognosia for hemiplegia of the upper limb. Critchley maintains that the vividness of the supernumerary phantom limb can be modified by mescaline, and that the percept disappears when the paralysed arm is moved in the direction of the phantom or when the affected left arm is touched by the patient's right arm.

Clinical reports of supernumerary phantom limbs after stroke are rare. ${ }^{4101314}$ Unlike the lack of awareness shown in most anosognosic phenomena, the experience of a phantom third limb is a positive phenomenon ${ }^{15}$ and raises theoretical questions about the nature of cognitive processes involved in conscious awareness. In the past, most of the reports have only provided scant details about the quality and extent of the patients' belief; little is known about how these patients behave when confronted with or challenged about the peculiarity of their belief. We now report a case of supernumerary phantom limb in a patient who was followed up for several months after his stroke.

\section{Patient description}

A 65 year old, right handed retired legal executive was admitted to hospital with a stroke on 8 August 1987. The symptoms included a left hemiplegia, poor concentration, 
left sensory loss, left hemianopia and the occasional denial that his left arm or leg were his own. Rationalisation for this denial stemmed from the belief that his left $\operatorname{limb}(\mathrm{s})$ had previously been amputated.

Relevant past history involved hospital admission in September 1985 for persisting diarrhoea, skin rash, arthritis and a weak right arm. Neurological symptoms also present at this time included temporary sensory loss and motor weakness in the right arm accompanied by finger/nose ataxia. CT scan revealed evidence of general cerebellar and cerebrum atrophy but no evidence of a focal lesion. The patient was finally diagnosed as having hypereosinophilic syndrome with polyarteritis nodosa; this required treatment with steroids after which there was rapid improvement. There was also a history of excessive alcohol drinking which had ceased three years previously.

On 19 October 1987, medical examination revealed a dense loss of sensation and proprioception with complete flaccid weakness of the left side. Visual fields were full to confrontation and there was no visual extinction. CT scan on 20 September 1987 showed a large intracerebral haematoma within the right basal ganglia with blood in the right lateral ventricle, third ventricle and fourth ventricle (fig 1).

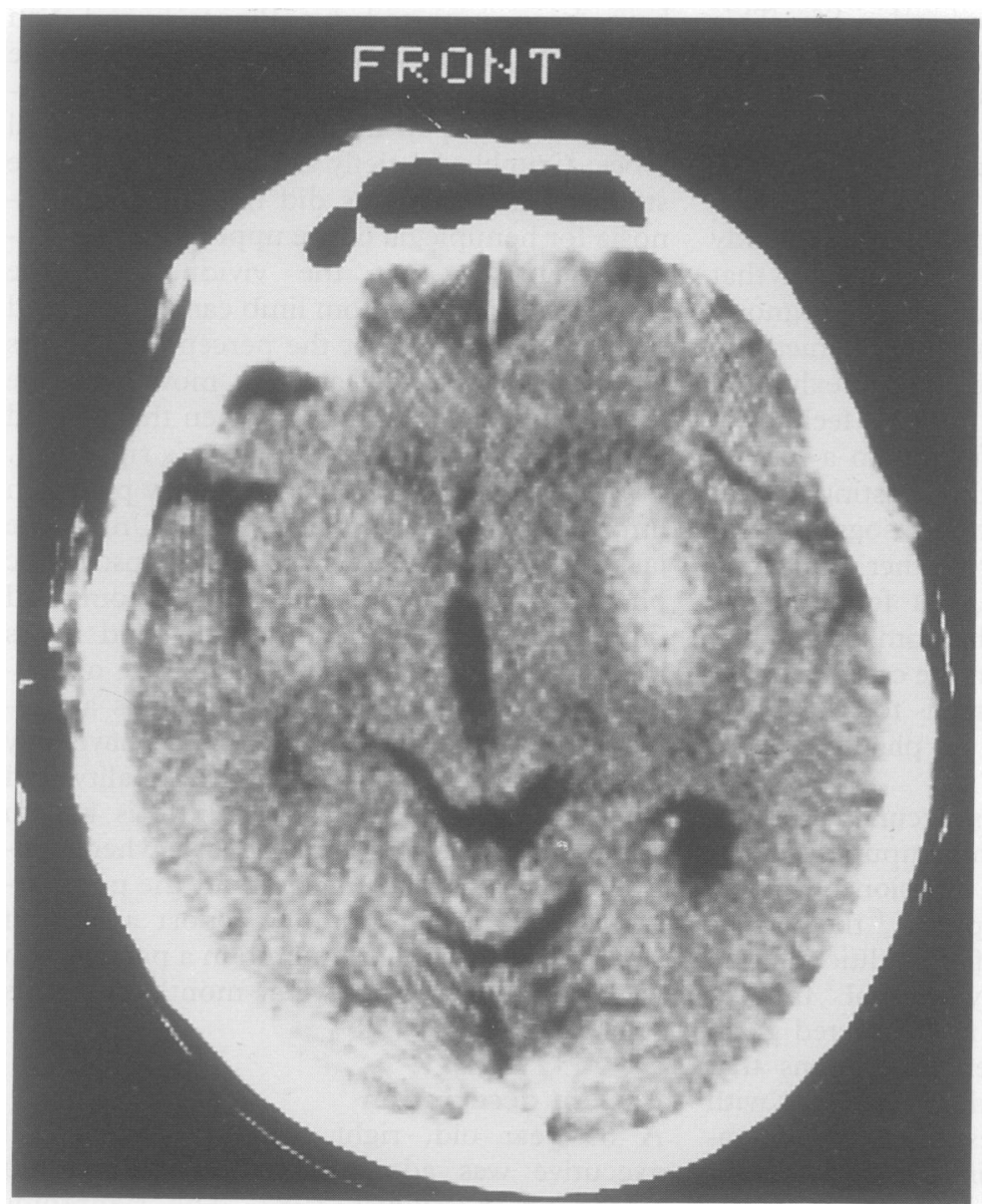

Figure 1 CT scan showing a large haematoma within the right basal ganglia.
Over the next 5 months there was minimal improvement in mobility and self care skills. Psychiatric investigations over this period concentrated on the patient's low mood, irritability and organic emotionalism but no hard biological features of depression were found. Discharged from the Rivermead Rehabilitation Centre on 2 April 1988 with a dense left hemiplegia and sensory loss, the patient continued to be dependent in many activities of daily living. His condition deteriorated and 6 months after discharge he died of bronchopneumonia.

\section{Neuropsychological investigations}

At Rivermead, the patient was evaluated on a number of cognitive and perceptual tests. On the Behavioural Inattention Test ${ }^{16}$ he showed impairment of visual attention on 3 of the 6 tests (letter cancellation, star cancellation and figure copying). When administered the National Adult Reading Scale (NART) ${ }^{17}$ on 2 November 1987 he made only two errors, yielding a predicted verbal IQ (VIQ) of 127 . Tested on the 5 verbal subtests from the WAIS$\mathrm{R}$ on the same date he obtained a VIQ of 116 . These scores are located in the high average to superior range. Immediate verbal memory was above average (Logical memory: immediate recall of 15.5), while delayed memory was normal for a man of his age. Performance subtests were attempted but were severely affected by visual difficulties. His direct copy of the Rey-figure was extremely poor (17/47). Delayed recall of the Rey (as a percentage of his original copy) was 0 . The patient showed no signs of perseverative behaviour, either in general conversation or on formal testing.

\section{Investigation of anosognosic phenomena}

When directly questioned at the Radcliffe Infirmary the patient had on several occasions denied ownership of his left arm and leg. On two separate occasions (25 September and 14 October 1987) he maintained that his left leg and arm had been amputated in 1964. No mention was made by clinical staff that the patient believed in the existence of a phantom third limb.

When admitted to Rivermead 2 months after his stroke, the patient was assessed for autotopagnosia; ${ }^{18}$ he could name all 18 bodily parts pointed to on the patient's own body, and on the examiner's body. Asked to execute a simple drawing of a man from memory, he produced an adequate representation which included a head, two arms, two legs and a torso (fig 2).

Anosognosic phenomena were formally assessed using Cutting's questionnaire ${ }^{3}$ on 22 October 1987. This revealed no explicit evidence of anosognosia for the hemiplegic limbs, non-belonging, or denial of the handicaps associated with stroke. Furthermore, the patient could not be described as showing anosodiaphoria as subsequent questioning revealed reasonable insight and concern about the effects of the stroke. The only anomalous and striking feature was his firmly held belief in the existence of a third arm which he claimed originated from the top left corner of his torso. 
Figure 2 The patient's drawing of a man.

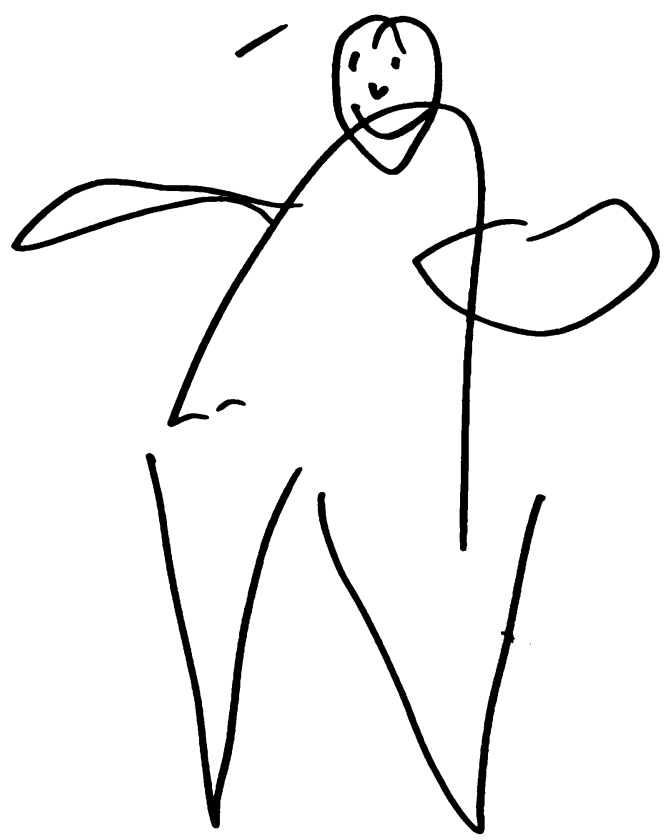

Unlike patients with other anosognosic phenomena which are usually observed in the acute stages of stroke, this patient was unusual in that he continued to hold a strong and persisting belief in the existence of a third arm for several months.

\section{Investigation of the phantom limb}

During the first three months at Rivermead, the patient was seen on many occasions to investigate and document his belief in the existence of a supernumerary phantom limb. While he reliably confirmed the belief in the existence of his "third arm" on each occasion, he was always unwilling to volunteer additional information unless specifically asked. On several later occasions (in November and December 1987) he specifically requested that this line of questioning be changed since the subject matter clearly disturbed him.

\section{INTERVIEWS}

On October 23, three days after admission, an interview with the patient was recorded to investigate the nature of his belief in the existence of a third arm, which he had mentioned during a clinical assessment the day before. At the time of the interview he was fully cooperative and seemed pleased to talk about himself and his previous work. The patient was mentally alert and coherent, scoring $9 / 10$ on the Hodkinson's mental orientation test, ${ }^{19}$ and he showed a good grasp of current affairs. Extracts from the interview follow (where $\mathrm{E}$ is the examiner and $\mathrm{P}$ the patient):

$E$ You had a stroke in fuly of this year?

$P$ Yes... I went along to see my local doctor because I was not feeling well. He decided to admit me to Radcliffe... brought me in by ambulance... I was in there for two weeks.

$E$ You told me that as a result of the stroke you can't move certain parts of your body?

$P$ That's right . . . the left side. It's a dense stroke as they call it... and I had a massive haemorrhage at the Radcliffe... I did not know I had it . . . but that's what my wife said to me... they took me to intensive care... and then they discharged me here.

$E$ What can you not do at the moment?

P I can't use my left hand or my left side... I can't do anything with them . . . it's a terrible stroke condition . . . it's like a sack of coal . . . I'm like an unguided missile . . . I fall all over the place.

E Can you tell me anything about your left hand?

$P$ I can't do anything with it!

$E$ Where is your left arm?

$P$ It's here (indicating with his head and eyes towards the left side).

$E$ Can you show it to me?

$P$ Yes (points to the left hand with the right hand).

E Can you just pick it up for me? (Does so) . . . Good. . . Is there any history attached to your hand?

$P$ No.

$E$ fust a normal hand?

$P$ That's right.

$E$ You were telling me yesterday something different about your hands?

$P$ Yes, I have a third one.

$E$ A third one?

$P$ Yes.

$E$ Where is that?

$P$ It is in the middle.

At this point, the patient was asked to indicate the "third limb" on the examiner's drawing of a man. His performance is shown in fig 3. The interview was then continued:

$E$ Can you show the middle one to me?

$P$ It's the dead one, it was taken off 20 years ago by $\operatorname{Dr}(X)$. . I' $m$ a bit vague about this, they tried to tell me I never had it off . . . a phantom limb. . . they tried to tell me I never had it off . . . I did . . I I know that.

$E$ Why did they take it off?

$P$ They took it off because presumably it needed taking off. . . I don't know, he's the surgeon.

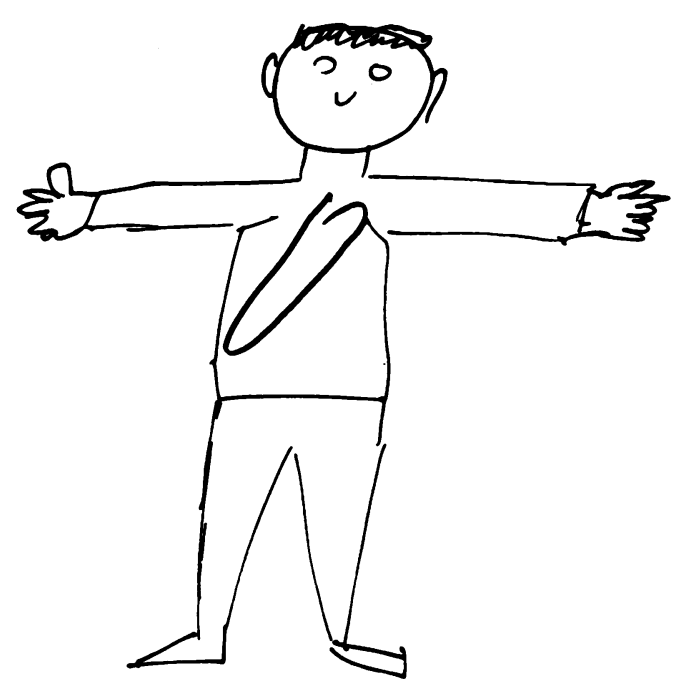

Figure 3 The patient's drawing of his "third arm" on the examiner's drawing of a man. 
E What do you think was wrong with your hand?

$P$ I think it was just a waste of time . . . it was doing nothing.

$E$ So tell me now at the moment, how many hands do you have?

$P$ Three.

E Three!... Show me your right hand (raises right arm). Count the number of hands you have for me.

P (Looking down and pointing)... One... two . . three.

$E$ How many actually work?

$P$ Tro.

$E$ Two of them work? Where are the good working hands located?

$P$ On the right side and the left side and the middle I suppose.

$E$ So which one does not work?

$P$ The one in the middle.

$E$ How is the middle one attached to your body?

$P$ It's not . . . it's attached but detached in the sense of it was taken off. . . I don't know. I really don't know. I'm in a muddle about this.

$E$ It's quite confusing, isn't it?

$P$ Yes, it is... I know that the right one is alright.

$E$ Can you move the left one?

$P$ Yes, I can but not very much . . . I can't do very much with it.

$E$ Where is the other hand that does not work?

$P$ In the middle... (pointing with right hand).

$E$ Does it fit under your clothes?

$P$ No, it does not... no, it is not covered with any clothes.

$E$ Does it get cold?

$P$ Yes, it does get cold.

$E$ Can you feel it?

$P$ Yes, I do!

$E$ So sometimes this third hand gets cold?

$P$ Yes, it does.

$E$ What do you think of a person having three hands?

$P$ It's an odd situation! . . . I'm a bit vague about it I must say.

After a short break the interview resumed:

$E O K$, now I want you to raise your right hand ( $P$ raises his right hand). Now raise your left hand (grasps his left hand with his right, and then raises it). Can you raise your middle hand?

P No, I can't . . . it's dead . . . it's not connected to me anymore.

$E$ Whereabouts is it?

$P$ It's tucked away down here! (Points to left side)... It's an artificial limb.

$E$ Can you touch it?

$P$ Yes, I can, I can find bits of it in the bed . . . it's in 3 pieces... I think.

$E$ How many legs do you have?

$P$ Three... no, only got two legs.

$E$ But you said you have three arms.

$P$ Yes, and this arm is an awful nuisance, keeps getting in the way.

$E$ Can you shake hands with this other arm?

$P$ No, I can't.

$E$ Could I touch it?

$P$ Yes, you could.

$E$ Could you show me where it is?
$P$ No, I can't.

$E$ Where has it gone now?

$P$ It's obviously wasted away.

$E$ Does it come back?

$P$ Yes, it does. They tell me that it was never taken off. . . I don't believe that.

$E$ Why do you think it's difficult to explain three arms?

$P$ It's an unusual number... unusual... I don't know. I'm in a muddle about it, I really don't know what to call it . . . I think it has just been left there . . . there seems to be quite a lot of heat in it. It's quite warm . . . warmer than the other hand.

$E$ Do you think the surgeons could do anything about it?

P I don't think they could do anything. I think they just left if there... it seemed tidier to do it.

$E$ Could they take it off again?

$P$ No, they could not . . . I don't know.

$E$ What did they do to your arm?

$P$ They took it off.

$E$ So if they took it off, then you would presumably have only one arm left wouldn't you?

$P$ That's right.

$E$ But you claim to have three arms!

$P$ Yes.

$E$ So it would seem as if they have given you another one back . . .?

$P$ Yes... . it's very confusing. . . I don't know what to do.

E I don't seem to have worked this out exactly . . . they took off your arm . . . and now you claim to have three arms . . . sounds confusing!

$P$ Yes I think so. . . I'm getting a bit tired.

$E$ Is there anything else you would like to mention?

$P$ No, I don't think so, it's very confusing . . . I agree with you, it does not seem to help at all. I don't seem to be as clear on the subject as I should be.

Subsequent discussions with the patient on 4 th and 9th of November, and on the 7th December confirmed his persisting belief in the existence of a "third arm" and his discomfort about holding such a belief. He maintained that the third hand was similar to his other hands and when asked indicated that the thumb of the "third arm" was located on the right side of the hand when the palm was below. The phantom would accordingly seem to be a left arm.

The following are excerpts from the interview on 9 November 1987 .

$E$ How is your right arm?

$P$ It's fine. But I had a dense stroke down the left side of my body.

$E$ Now, tell me about your left arm.

$P$ There seems to be a problem about that... I had one arm amputated in the Radcliffe . . . It was in October 1964, October the twentieth under $\operatorname{Dr}(X)$.

$E$ Which arm was amputated?

$P$ It was the left and there's another one, a middle one.

$E$ Can you point to your left arm? ( $P$ does so.)

$P$ That's the left one... it's very thin. There appears to be a third one.

$E$ Whereabouts is the third one? 
$P$ In the middle of the other two. You can see three sometimes.

$E$ Does that mean that sometimes you can't see three?

$P$ That's right.

$E$ Can you see three now?

$P$ No, just two... I sometimes see the third arm.

E Can you feel it?

$P$ Yes, occasionally.

$E$ Do you feel you can move it?

$P$ I can move it a little bit . . . but it's an effort. Normally I can't move it.

E Can you feel a touch on it?

$P$ I don't know about that.

$E$ At the moment, how many arms do you have?

$P$ Two, with an occasional third. I'm not sure why I had it amputated.

E How many arms did you have before one was amputated?

$P$ Two.

E Whereabouts was the one that was amputated?

$P$ It was my left one, I think.

$E$ If your left arm was amputated, which arm is this (E points to P's left arm)?

$P$ The right one.

$E$ And which arm is this (E points to P's right arm)?

$P$ I couldn't tell you. It sounds nonsense I know.

$E$ fust tell me again, which arm is this ( $E$ points to P's right arm)?

$P$ The right one.

$E$ And this one (E points to P's left arm)?

$P$ The left one.

$E$ And which arm was amputated?

$P$ The left one. There are limits to the amount that you question me about this. It's a nonsense I know.

To investigate the possibility of a more basic disorder of calculation, we examined the patient's simple arithmetic the next day (10 November 1987). This interview was structured to elicit "abstract" calculation before the patient was required to report the number of arms he perceived himself to have.

$E$ How's your arithmetic?

P Fairly good . . . I sometimes had to look at the accounts.

$E$ So if $I$ asked you what one and one is, you would say. . .?

$P$ Two.

$E$ And two plus one...?

$P$ Is three.

E Three minus one?

$P$ That would make two.

$E$ And two minus one?

$P$ One. This is not difficult.

E How many arms do people usually have?

$P$ Two.

$E$ And if someone lost an arm, they would have?

$P$ fust the one.

$E$ How many arms do you have?

$P$ Three.

$E$ How did that happen?

$P$ I had one amputated.

$E$ If you had two arms and one was amputated, how many arms would you have?

$P$ Two... or three. I know it's a nonsense. I don't know whether I'm coming or going.

At this point the patient began to show signs of agitation and we finished this line of investigation.

Writing with the "left" hand

An incident related to the foregoing descriptions of the phantom limb occurred during the November follow up. On this occasion the patient was involved in several tasks which required him to draw and write with his nonaffected right hand. Towards the end of one session, he was requested to write his signature on a blank page. Picking up the pen with his right hand, he wrote his signature which, although slightly unstable, was accomplished with ease. A copy of this signature using the right hand is shown in fig 4a. When he put down the pen with his right hand, the patient was asked if he could write his signature with his left hand (he had previously declared that the "third arm" was not capable of being controlled directly by him for such a task). To our surprise, he said that he could write his signature with his left arm. Requested to do so, he picked up the pen with his right hand and proceeded to write a second signature directly below the first. This second signature (performed approximately one minute after the previous attempt) contained only his surname. A copy of this signature using what the patient "believed" to be his left hand is shown in fig $4 \mathrm{~b}$.

Inspection of the two signatures reveals considerable constructional and stylistic differences, differences one would not expect from a patient writing his signature twice in succession with an unaffected hand. The first signature (fig $4 \mathrm{a}$ ) shows strong pen pressure and good fluency while figure $4 \mathrm{~b}$ displays poor construction and lighter pen pressure.

The patient's acknowledgement that he could use his left arm to write represents the first and only instance of what might be described as "implicit" anosognosia or "denial of handicap". ${ }^{20}$ That is, although direct questioning produced awareness of the physical deficits associated with his stroke, this partic-
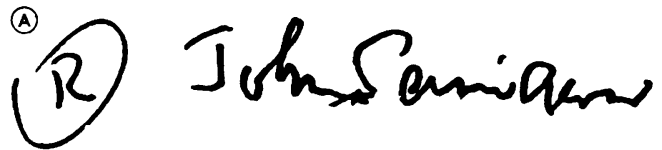

(B)
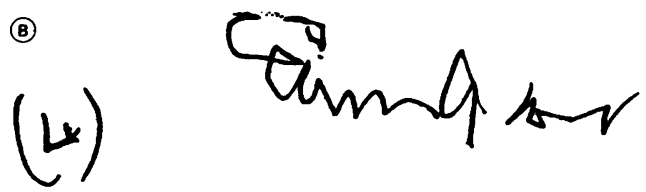

Figure 4 a) (top) Copy of the patient's signature using his right hand; $b$ ) (bottom) Copy of the patient's signature with what he claimed to be his left hand but which was performed using his right hand 
ular indirect request showed a lack of awareness of one of the major consequences of his left sided hemiplegia. Unfortunately, it was not possible to pursue these investigations further at this stage; probing discussions on the subject of his arms clearly disturbed the patient.

\section{Discussion}

The main point to stress in any discussion of the patient's behaviour is that he appeared completely rational on all topics broached other than those concerning the "third arm". Indeed, even with respect to this delusional belief, normal rationality is not far removed as the patient was well aware of the irrationality of what he claimed to be experiencing. Thus to argue that the patient is "merely confused" would fail to do justice to the complexity of his otherwise apparently normal cognition. To argue that his delusion is "encapsulated" would fail to capture his at times considerable insight into the oddity of his own beliefs. ${ }^{21}$ Psychodynamic explanations in the traditional sense of the term ${ }^{22}$ are not appropriate. The patient's "third arm" is not a defensive reaction to his impairment; the "third arm" provokes annoyance and dismay rather than psychological benefit. ${ }^{21}$

Any interpretation of the patient's "delusion" must accordingly account for the rationality of his thoughts as well as the bizarre conclusions to which some of them lead him. His "psychopathology" cannot simply be explained at the level of an encapsulated delusional belief system since it is apparent that he often has good access to the nature of what is irrational in his thought processes. The analytic task is thus to give a cognitive explanation of the patient's "reasoning" that covers both his reasonable and his "pathological" beliefs.

The most straightforward account would seem to be this:

1) The brain damage sustained by the patient is the proximal and sufficient cause of his left hemiplegia and dense loss of left-sided sensation. Furthermore, he is clearly aware of the consequences of his stroke: "I can't use my left hand or left side."

2) This sensory impairment is analogous to the loss of afferent information after lesion of the peripheral nerves, the brachial plexus, the spinal roots, or the spinal cord. ${ }^{62324}$

3) Just as destruction of the sensory roots often leads to the phenomenological experience of a supernumerary third limb, so in this case, severe sensory and proprioceptive loss provokes the innate "neuromatrix" of the body image into constructing a phantom. Levine, Calvanio and Rinn ${ }^{25}$ interpret this phenomenon in terms of "perceptual completion".

4) The patient now needs to explain to himself the phenomenological reality of this phantom arm, located on the left side of his body, in the light of his otherwise intact awareness of the world. He attempts to explain the existence of the third arm in terms of what he understands about "phantom limbs". The patient himself initially refers to his "third" arm both as an "artificial limb" and as a "phantom limb". The examiners never referred to it as such in front of the patient. It is no esoteric medical knowledge that phantoms are frequently felt after amputation and accordingly the patient concludes that to explain the phantom he must have undergone an amputation of a limb. As an intelligent, well educated man, he then attempts to explain the existence of the third limb in terms of two hypotheses. (He appears unable to accept the existence of the phantom without attempting to explain it.)

5) He conjectures that his "real" left arm has been amputated, and that he accordingly suffers from (and undoubtedly feels) a phantom left arm. This hypothesised amputation has the effect of sustaining and supporting his percept of a third arm. The hypothesis cannot, however, be entirely satisfactory to him. On formal questioning throughout our interviews he is consistently aware that he does have a real left arm (albeit one that is paralysed); that is, he does not demonstrate anosognosia for hemiplegia. Since knowledge of supernumerary phantom limb after stroke is specialised medical information (not part of the general knowledge of most educated people), the patient is forced into an even more bizarre hypothesis.

6) He conjectures that he really did once have a genuine third arm ("dead arm" or "middle arm") which was then amputated. But this hypothesis is likewise not satisfactory to the patient who on direct questioning shows that he knows full well that he had a normal complement of arms (namely two) before his stroke (and hence before the purported "amputation" of one of them).

Thus, however, he manipulates these two hypotheses, but they can only account for some not all of the data available to him (where those data include the constraints of arithmetic, general knowledge, logical reasoning, autobiographical knowledge and phenomenological experience). The absurdity of these tentative explanations is shown up when the patient upon formal questioning is forced to re-examine their veracity. His "confusion" ("It's a nonsense I know") is well justified but he can do no better in interpreting to himself the full range of consequences of his brain damage. The patient's "numerical" confusion follows from his switching between these two inadequate hypotheses. If he consistently believed that his (real) left arm had been amputated he could (at worst) claim to have two arms; a real right arm and a phantom left arm. But since he is aware of the presence of his (paralysed) left arm, the phantom must be a third arm. In all these respects, the patient's manifest disquiet is a reflection of "cognitive dissonance ${ }^{\text {26 }}$ that cannot logically be resolved given the two hypothetical explanations put forward. The belief system always comes full circle, and is self-perpetuating despite its conspicuous inadequacy. This description concludes our first hypothesis.

There are, however, problems with this explanation. Supernumerary phantom limb 
consequent upon lesions of the CNS is an extremely rare phenomenon. Yet left hemiparesis, left sensory loss, and left neglect are common after right hemisphere damage, including basal ganglia stroke. ${ }^{27}$ Why then do the vast majority of these patients not experience a supernumerary phantom? We have mentioned previously that in patients who experience a phantom after amputation, that phantom usually disappears if a cerebral lesion is subsequently sustained. ${ }^{5}$ In our case, the phantom is consequent upon a cerebral lesion. Accordingly, a tentative alternative explanation for the patient's "delusional belief" is that the phantom may be a derived phenomenon; that is, it may be produced by unconscious cognitive processes that are a response to his fluctuating awareness of his primary neurological deficits.

A second hypothesis argued along the following lines may thus be possible. Although the patient usually showed reasonable insight into the fact that his left arm was paralysed, there are some occasions when he did not appear to be fully aware of his hemiparesis. If therefore he represented to himself the two propositions my left arm is paralysed and my left arm is not paralysed, this would lead to a classic contradiction in a logical system. It is a characteristic of any standard logistic system that from such a contradiction any and all propositions can be derived. If we assume that for ordinary people (as opposed to logicians), the propositions actually drawn from a contradiction must be relevant to the initial premises, ${ }^{28}$ then an appropriate conclusion from the three premises: 1) I have a normal right arm, 2) I have a paralysed left arm and 3) I have a normal left arm is indeed $I$ have three arms. That is, I must have two arms to the left of my right arm.

It may be that the patient drew such an (unconscious) inference, but because the remainder of his cognitive system was intact, he was, in addition, acutely aware that any such conclusion was, in his own words, "a nonsense". He cannot fully believe the conscious product of his unconscious reasoning. Consequently, further attempts to probe the details of this contradictory delusional belief usually led to the patient becoming agitated, confused and upset. The critical premise for the establishment of this line of argument is, of course, the claim that the patient sometimes entertained the proposition my left arm is not paralysed. There is some (albeit admittedly weak) evidence for this in our interviews. For the most part, the patient is well aware of his left hemiplegia. We do, however, sometimes see fluctuation in this awareness, as when he claims that at least two of his hands work, and that he can move the left one a little. There is likewise the claim by the patient that he can use his left hand to write when so requested. Also pertinent are the repeated early reports (at the Radcliffe Infirmary) that he denied that his left arm belonged to him. This might provide further ground for the belief that my left arm is not paralysed. Strictly speaking, it would be true (or at least not false) to claim that my left arm is not paralysed in circumstances where I do not have a left arm.

The patient's conscious rationalisations for the presence of the phenomenological third arm would then proceed as in the previous account we gave. The two interpretations differ in one respect only. On the first hypothesis, the supernumerary phantom is a direct result of brain damage; on the second, the phenomenological experience of the phantom is itself mediated by the way in which the patient comes to represent the effects of his hemiplegia to himself. Although sensory and motor loss are usually found together (as in our case) our second (derived) hypothesis suggests that the supernumerary phantom is determined more by motor than by sensory loss. Cases of supernumerary phantom have been observed after both left and right hemiparesis (see introduction). By contrast, an association with somatosensory receiving areas and adjacent parietal cortex would be more consistent with our first hypothesis. ${ }^{6}$

There is nothing intrinsically implausible about our second hypothesis. It is known, for example, that conceptually-driven "experience" can be phenomenologically indistinguishable from perceptually-driven experience in normal subjects. ${ }^{29}$ Likewise, many visual illusions bear witness to the fact that unconscious inference can create phenomenologically real percepts that the normal subject "knows" to be ridiculous, without that knowledge influencing in any way the phenomenological reality of the percept; the Ames room provides one such example ${ }^{30}$ (see also Shallice $^{31}$ ). When a non-rectangular room is constructed to appear rectangular from a given vantage point, then a person walking along the rear wall will appear to shrink and grow. In the pathological literature, it is similarly possible that certain reduplicative paramnesias (Capgras syndrome, for example) have a strong cognitive component. The phenomenological experience that impostors have been substituted for family members ${ }^{32}$ could be cognitively derived from more basic prosopagnosic and affective impairments. ${ }^{33}$

Although serious study of these topics is only just beginning, ${ }^{34}{ }^{35}$ both explanations appear consistent with the general framework for the interpretation of anosognosic phenomena put forward by Bisiach and Geminiani. ${ }^{21}$ We also note that the apparent rarity of supernumerary phantoms after cerebral lesions may be misleading; such phenomena could be more common were investigators to specifically look for them. This study was supported by the Medical Research Council,
and the Stroke Association. We are also grateful to Dr Malar Hunt for providing details on the patient and Dr Ian Robertson for translation from the German.

1 McGlynn S, Schacter D. Unawareness of deficits in neuropsychological syndromes. 7 Clin Experi Neuropsycho 1989;11:43-205.

2 Levine D. Unawareness of visual and sensorimotor defects: a hypothesis. Brain Cognition 1990;13:233-81.

3 Cutting J. Study of anosognosia. F Neurol Neurosurg Psy chiatry 1978;41:548-55.

4 Critchley M. The parietal lobes. New York: Hafner, 1953.

5 Fredericks J. Phantom limb and phantom limb pain. In Fredericks J, ed. Handbook of clinical neurology, vol 1 (45), Clinical neuropsychology. Amsterdam: Elsevier, 1985. 
6 Melzak R. Phantom limbs and the concept of a neuromatrix. Trends in Neuroscience 1990;13:88-92.

7 Cutting J. Body image disturbances in neuropsychiatry. : Reynolds E, Trimble M, eds. The bridge between neurology and psychiatry. Edinburgh: Churchill Livingstone, 1989. lesions. Brain 1911;34:102-254.

9 Appenzeller O, Bicknell J. Effects of nervous system lesions on phantom experience in amputees. Neurology 1969; 19:141-6.

10 Ehrenwald $H$. Verandertes Erleben des Korperbildes mit konsekutiver Wahnbildung bei linkseitiger Hemiplegie. Monatsschrift fur Psychiatrie und Neurologie 1930;75: 89-97.

11 Pineas H. Ein Fall von phantomahnlichen Erscheinungen ("Phantomarm") bei hemiplegischer Lahmung. Nervenarzt 1932;5:233-6.

12 Van Bogaert L. Sur la pathologie de l'image de soi. Ann Medico-Psychol 1934;92:419-555.

13 Gilliatt R, Pratt R. Disorders of perception and performance in a case of right-sided cerebral thrombosis. F Neuro Neurosurg Psychiatry 1952;15:264-71.

14 Fredericks J. Occurrence and nature of phantom limb phenomena following amputation of body parts and following lesions of the central and peripheral nervous system. Psychiatry Neurol Neurochir 1963;66:73-97.

15 Halligan P, Cockburn J, Wilson B. The behavioural assessment of visual neglect. Neuropsychol Rehab 1991;1:5-32.

16 Jackson $H$. On the comparative study of diseases of the nervous system. Selected writings, vol 2 . New York: Basic
newson $H$. On the comparative study of diseases of the nervous system. Selec

17 Nelson H, O'Connell A. Dementia: the estimation of premorbid intelligence levels using a new adult reading test. Cortex 1978;14:234-44.

18 Semenza C, Goodglass H. Localization of body parts in brain injured subjects. Neuropsychologia 1985;23. 161-75.

19 Hodkinson H. Evaluation of a mental test score for assessment of mental impairment in the elderly. Age and ageing 1972;1:233-8.

20 House A, Hodges J. Persistent denial of handicap after infarction of the right basal ganglia: a case study. $\mathcal{f}$ Neurol Neurosurg Psychiatry 1988;51:112-5.

21 Bisiach E, Geminiani G. Anosognosia related to hemiplegia and hemianopia. In: Prigatano G, Schacter D, eds. Awareness of deficit after brain injury: clinical and theoretical issues. New York: Oxford University Press, 1991.

22 Weinstein E, Kahn R. Denial of illness. Springfield: Charles C Thomas, 1955.

23 Mayer-Gross W. Ein Fall von Phantomarm nach Plexuszerreizung. Nervenartz 1929;2:65-72.

24 Riddoch G. Phantom limbs and body shape. Brain 1941;64:197-222.

25 Levine D, Calvanio R, Rinn W. The pathology of anosognosia for hemiplegia. Neurology 1991;41:1770-81.

26 Festinger L. $A$ theory of cognitive dissonance. Evanston, Illinois: Row, Peterson, 1957.

27 Damasio A, Damasio H, Chang Chui H. Neglect following damage to frontal lobe or basal ganglia. Neuropsychologia 1980;18:123-32.

28 Sperber D, Wilson D. Relevance: communication and cognition. Oxford: Blackwell, 1986.

29 Perky C. An experimental study of imagination. Am $\mathrm{f}$ Psychol 1910;21:422-52.

30 Ames A. Some demonstrations concerned with the origin and nature of our sensations. Dartmouth: Dartmouth Eye nature of our sens
Institute, 1946.

31 Shallice T. From neuropsychology to mental structure. Cambridge: Cambridge University Press, 1988.

32 Alexander MP, Stuss DT, Benson DF. Capgras syndrome: a reduplicative phenomenon. Neurology 1979;29:334-9.

33 Ellis H, Young A. Accounting for delusional misidentifications. Br F Psychiatry 1990;157:239-48.

34 Cutting J. The right cerebral hemisphere and psychiatric disorders. Oxford: Oxford University Press, 1990.

35 Fleminger S. Seeing is believing: the role of "preconscious" perceptual processing in delusional misidentification. $\mathrm{BrF}$ Psychiatry 1992;160:293-303. 